\begin{tabular}{|c|c|}
\hline Title & A ctivation cross sections of al pha induced reactions on natural ytterbium up to $50 \mathrm{MeV}$ \\
\hline Author(s) & $\begin{array}{l}\text { Saito, Moemi; A ikawa, Masayuki; Murata, Tomohiro; Ukon, Naoyuki; Komori, Y ukiko; Haba, Hiromitsu; T akács, } \\
\text { Sándor }\end{array}$ \\
\hline Citation & $\begin{array}{l}\text { Nuclear Instruments and Methods in Physics Research Section B: Beam Interactions with Materials and A toms, } 453 \text {, } \\
\text { 15-21 } \\
\text { https://doi.org/10.1016/.nimb.2019.05.074 }\end{array}$ \\
\hline Issue Date & $2019-08-15$ \\
\hline Doc URL & http:/hdl.handle.net/2115/81647 \\
\hline Rights & $\begin{array}{l}\text { (02019. This manuscript version is made available under the CC-BY-NC-ND } 4.0 \text { license } \\
\text { http://creativecommons.org/icenses/by-nc-nd/4.0/ }\end{array}$ \\
\hline Rights(URL) & http://creativecommons.org/icenses/by-nc-nd/4.0/ \\
\hline Type & article (author version) \\
\hline File Information & NIMPR B453_15-21.pdf \\
\hline
\end{tabular}

Instructions for use 


\title{
Activation cross sections of alpha-induced reactions on natural ytterbium up to $50 \mathrm{MeV}$
}

\author{
Moemi Saito ${ }^{1, *}$, Masayuki Aikawa ${ }^{1,2}$, Tomohiro Murata ${ }^{1}$, Naoyuki Ukon³ ${ }^{3}$ Yukiko Komori", \\ Hiromitsu Haba ${ }^{4}$, Sándor Takács ${ }^{5}$ \\ ${ }^{1}$ Graduate School of Biomedical Science and Engineering, Hokkaido University, Sapporo 060-8638, Japan \\ ${ }^{2}$ Faculty of Science, Hokkaido University, Sapporo 060-0810, Japan \\ ${ }^{3}$ Advanced Clinical Research Center, Fukushima Medical University, Fukushima 960-1295, Japan \\ ${ }^{4}$ Nishina Center for Accelerator-Based Science, RIKEN, Wako 351-0198, Japan \\ ${ }^{5}$ Institute for Nuclear Research, Hungarian Academy of Sciences (ATOMKI), 4026 Debrecen, Hungary
}

\begin{abstract}
Activation cross sections of $\alpha$-particle induced reactions on ${ }^{\text {nat }} Y \mathrm{~b}$ were measured. Stacked foil technique, activation method and $\gamma$-ray spectrometry were used. The stacked target consisted of nat $\mathrm{Yb}$ and ${ }^{\text {nat }} \mathrm{Ti}$ foils was irradiated with a 51.0-MeV $\alpha$ beam at the RIKEN AVF cyclotron. The $\gamma$ rays emitted from the irradiated foils were measured using a high-resolution HPGe detector. Production cross sections of ${ }^{170,171,172,173,175} \mathrm{Hf}$,

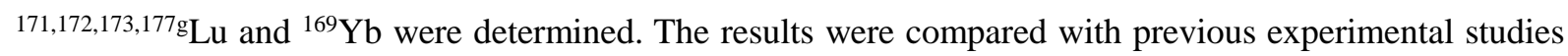
and theoretical calculations. For most of the reactions a consistent agreement was found.
\end{abstract}

\section{Keyword}

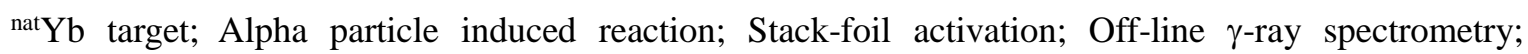
Excitation function; ${ }^{177}$ Lu-medical isotope

\section{Introduction}

Many radioisotopes can be used for medical investigations and/or treatments. One candidate of such medical radioisotopes is ${ }^{177 \mathrm{~g}} \mathrm{Lu}\left(\mathrm{T}_{1 / 2}=6.647 \mathrm{~d}\right)$ [1]. It decays with emissions of a $\beta^{-}$particle $\left(\mathrm{E}_{\text {mean }}=134.2\right.$ $\mathrm{keV}$ ) and $\gamma$ rays (e.g., $\mathrm{E}_{\gamma}=112.95 \mathrm{keV}$ and $208.37 \mathrm{keV}$ with $\mathrm{I}_{\gamma}=6.17 \%$ and $10.36 \%$, respectively). ${ }^{177 g} \mathrm{Lu}$ is useful for theranostic application (therapy + diagnosis) because the energy of the $\beta^{-}$particles and $\gamma$ rays are suitable for theraputic and diagnostic investigations, respectively.

For practical use of ${ }^{177 g} \mathrm{Lu}$, every production reaction and all possible side reactions of the by-products should be investigated. Beside neutron production routes there are several charged-particles induced reactions to produce ${ }^{177 g} \mathrm{Lu}$. We focused on charged-particle reactions on ${ }^{\text {nat}} \mathrm{Yb}$ which has seven stable isotopes ${ }^{168} \mathrm{Yb}$ : 0.13\%, ${ }^{170} \mathrm{Yb}: 3.04 \%,{ }^{171} \mathrm{Yb}: 14.28 \%,{ }^{172} \mathrm{Yb}: 21.83 \%,{ }^{173} \mathrm{Yb}: 16.13 \%,{ }^{174} \mathrm{Yb}: 31.83 \%$, and $\left.{ }^{176} \mathrm{Yb}: 12.76 \%\right)$. The radionuclide ${ }^{177 g} \mathrm{Lu}$ can be produced in the $(\mathrm{p}, \gamma)$ and $(\mathrm{d}, \mathrm{n})$ reactions on ${ }^{176} \mathrm{Yb}$ and the $\alpha$-particle induced reactions on ${ }^{174} \mathrm{Yb}$ and ${ }^{176} \mathrm{Yb}$. In this paper, the ${ }^{\text {nat }} \mathrm{Yb}(\alpha, \mathrm{x})^{177 \mathrm{~g}} \mathrm{Lu}$ reaction cross-section among other possible

\footnotetext{
*Corresponding author: moemi@nds.sci.hokudai.ac.jp
} 
reactions on ${ }^{\text {nat }} \mathrm{Yb}$ was investigated.

Only one previous study of the ${ }^{\text {nat }} \mathrm{Yb}(\alpha, \mathrm{x})^{177 g} \mathrm{Lu}$ reaction [2] could be found in the EXFOR database [3]. The previous study shows production cross sections of ${ }^{177 g} \mathrm{Lu}$ up to $37.7 \mathrm{MeV}$. Therefore, it is worth performing an additional experiment to extend the data up to $50 \mathrm{MeV}$ and to increase reliability of the available cross section data. In addition, production cross sections of the by-products, ${ }^{170,171,172,173,175} \mathrm{Hf}$, ${ }^{171,172,173} \mathrm{Lu}$ and ${ }^{169} \mathrm{Yb}$, were also determined.

\section{Experimental}

The experiment was performed by using the AVF cyclotron at the RI Beam Factory, RIKEN, Japan. The stacked foil technique, the activation method and the high-resolution $\gamma$-ray spectrometry were used. The stacked target consisted of pure metallic foils of nat $\mathrm{Yb}$ (99\% purity, Goodfellow Co., Ltd., UK) and ${ }^{\text {nat }} \mathrm{Ti}$ (99.6\% purity, Nilaco Corp., Japan). The ${ }^{\text {nat } T i ~ f o i l s ~ w e r e ~ i n s e r t e d ~ i n t o ~ t h e ~ s t a c k ~ f o r ~ m o n i t o r i n g ~ t h e ~ b e a m ~}$ parameters and target thicknesses via the ${ }^{\text {nat }} \mathrm{Ti}(\alpha, \mathrm{x})^{51} \mathrm{Cr}$ reaction by determining the excitation function of the reaction and comparing to the recommended values provided in one of the database maintained by the IAEA [4]. The size and weight of the nat Yb foils ( 3 pieces, $\left.25 \times 25 \mathrm{~mm}^{2}\right)$ and nat Ti foil $\left(1\right.$ piece, $\left.50 \times 100 \mathrm{~mm}^{2}\right)$ were measured and the thickness of each foil was determined, which were found to be $16.60,16.32,17.11 \mathrm{mg} / \mathrm{cm}^{2}$ for the ${ }^{\text {nat }} \mathrm{Yb}$ foils and $2.40 \mathrm{mg} / \mathrm{cm}^{2}$ for the nat Ti foil, respectively. The foils were cut up for $8 \times 8 \mathrm{~mm}^{2}$ pieces to fit into the target holder. The irradiation of the target was done in vacuum. The $\alpha$-particle beam energy was measured as $51.0 \mathrm{MeV}$ by the TOF method [5]. The beam was collimated down to a $3 \mathrm{~mm}$ diameter. The irradiation lasted for 2 hours. The average beam intensity measured with a Faraday-cup was 413.9 nA. Energy degradation of the bombarding particles in the target was calculated by the SRIM code [6]. No electron suppression voltage was applied for the Faraday-cup since its geometry assured that the solid angle in which the secondary electrons could escape was small.

The irradiated foils were separated each other from the stack after the end of bombardment. The $\gamma$-ray spectra of each irradiated foil were measured without chemical separation. To follow the decay of the reaction products with half-lives between $12.1 \mathrm{~h}$ and $1.87 \mathrm{y}$ spectra were measured five times. The cooling times of the measurements are 10 hours, 33 hours, 3.1 days, 14.1 days and 143 days, respectively. A high-resolution HPGe detector (ORTEC GEM-25185-P) was used for the $\gamma$-ray spectrometry. The detector efficiency was calibrated by using a standard $\gamma$-ray point source consisted of a mixture of multiple radioisotopes ${ }^{57,60} \mathrm{Co},{ }^{88} \mathrm{Y}$, ${ }^{109} \mathrm{Cd}$, ${ }^{113} \mathrm{Sn}{ }^{137} \mathrm{Cs}$, ${ }^{139} \mathrm{Ce}$ and ${ }^{241} \mathrm{Am}$. The $\gamma$ lines detected by the detector were analyzed by the software Gamma Studio (SEIKO EG\&G). Reaction and decay data for $\gamma$-ray spectrometry were taken from NuDat 2.7 [7], Lund/LBNL Nuclear Data Search [8], LiveChart [9] and QCalc [10], which are given in Table 1. For the

${ }^{171} \mathrm{Hf}$ radionuclide, only relative $\gamma$ intensities were provided in the Lund/LBNL data library [8]. Thus, the factor to obtain absolute intensities was taken from Baglin (2002) [11]. The derivation of the $\gamma$ intensity of ${ }^{171} \mathrm{Hf}$ was the same way as in Király et al. (2008) [2].

Table 1. Decay data and contributing reactions of the investigated reaction products [7-11] 


\begin{tabular}{|c|c|c|c|c|c|c|}
\hline Nuclide & Half-life & Decay mode $(\%)$ & $\mathrm{E}_{\gamma}(\mathrm{keV})$ & $\mathrm{I}_{\gamma}(\%)^{*}$ & Contributing reactions & $\begin{array}{l}\text { Q-value } \\
(\mathrm{MeV})\end{array}$ \\
\hline \multirow[t]{5}{*}{${ }^{175} \mathrm{Hf}$} & $70 \mathrm{~d}$ & $\varepsilon(100)$ & 343.40 & $84 \pm 3$ & ${ }^{171} \mathrm{Yb}(\alpha, \gamma)$ & -2.4 \\
\hline & & & & & ${ }^{172} \mathrm{Yb}(\alpha, \mathrm{n})$ & -10.4 \\
\hline & & & & & ${ }^{173} \mathrm{Yb}(\alpha, 2 \mathrm{n})$ & -16.8 \\
\hline & & & & & ${ }^{174} \mathrm{Yb}(\alpha, 3 \mathrm{n})$ & -24.3 \\
\hline & & & & & ${ }^{176} \mathrm{Yb}(\alpha, 5 \mathrm{n})$ & -36.9 \\
\hline \multirow[t]{5}{*}{${ }^{173} \mathrm{Hf}$} & $23.6 \mathrm{~h}$ & $\varepsilon+\beta^{+}(100)$ & 123.68 & $83 \pm 4$ & ${ }^{170} \mathrm{Yb}(\alpha, \mathrm{n})$ & -11.0 \\
\hline & & & 296.97 & $33.9 \pm 1.4$ & ${ }^{171} \mathrm{Yb}(\alpha, 2 \mathrm{n})$ & -17.6 \\
\hline & & & & & ${ }^{172} \mathrm{Yb}(\alpha, 3 \mathrm{n})$ & -25.6 \\
\hline & & & & & ${ }^{173} \mathrm{Yb}(\alpha, 4 \mathrm{n})$ & -32.0 \\
\hline & & & & & ${ }^{174} \mathrm{Yb}(\alpha, 5 \mathrm{n})$ & -39.5 \\
\hline \multirow[t]{6}{*}{${ }^{172} \mathrm{Hf}$} & $1.87 \mathrm{y}$ & $\varepsilon(100)$ & 125.81 & $11.3 \pm 0.9$ & ${ }^{168} \mathrm{Yb}(\alpha, \gamma)$ & -2.8 \\
\hline & & & & & ${ }^{170} \mathrm{Yb}(\alpha, 2 \mathrm{n})$ & -18.1 \\
\hline & & & & & ${ }^{171} \mathrm{Yb}(\alpha, 3 \mathrm{n})$ & -24.7 \\
\hline & & & & & ${ }^{172} \mathrm{Yb}(\alpha, 4 \mathrm{n})$ & -32.7 \\
\hline & & & & & ${ }^{173} \mathrm{Yb}(\alpha, 5 \mathrm{n})$ & -39.1 \\
\hline & & & & & ${ }^{174} \mathrm{Yb}(\alpha, 6 \mathrm{n})$ & -46.5 \\
\hline \multirow[t]{5}{*}{$171 \mathrm{gHf}$} & $12.1 \mathrm{~h}$ & $\varepsilon+\beta^{+}(100)$ & 662.1 & $14.6 \pm 1.7$ & ${ }^{168} \mathrm{Yb}(\alpha, \mathrm{n})$ & -11.8 \\
\hline & & & & & ${ }^{170} \mathrm{Yb}(\alpha, 3 \mathrm{n})$ & -27.1 \\
\hline & & & & & ${ }^{171} \mathrm{Yb}(\alpha, 4 \mathrm{n})$ & -33.7 \\
\hline & & & & & ${ }^{172} \mathrm{Yb}(\alpha, 5 \mathrm{n})$ & -41.8 \\
\hline & & & & & ${ }^{173} \mathrm{Yb}(\alpha, 6 \mathrm{n})$ & -48.1 \\
\hline \multirow[t]{4}{*}{${ }^{170} \mathrm{Hf}$} & $16.01 \mathrm{~h}$ & $\varepsilon(100)$ & 164.71 & $26 \pm 7$ & ${ }^{168} \mathrm{Yb}(\alpha, 2 \mathrm{n})$ & -19.0 \\
\hline & & & & & ${ }^{170} \mathrm{Yb}(\alpha, 4 \mathrm{n})$ & -34.4 \\
\hline & & & & & ${ }^{171} \mathrm{Yb}(\alpha, 5 \mathrm{n})$ & -41.0 \\
\hline & & & & & ${ }_{172} \mathrm{Yb}(\alpha, 6 \mathrm{n})$ & -49.0 \\
\hline \multirow[t]{3}{*}{$177 \mathrm{gLu}$} & $6.647 \mathrm{~d}$ & $\beta^{-}(100)$ & 208.37 & $10.36 \pm 0.07$ & ${ }^{174} \mathrm{Yb}(\alpha, \mathrm{p})$ & -9.4 \\
\hline & & & & & ${ }^{176} \mathrm{Yb}(\alpha, \mathrm{t})$ & -13.6 \\
\hline & & & & & ${ }^{176} \mathrm{Yb}\left(\alpha,{ }^{3} \mathrm{He}\right){ }^{177} \mathrm{Yb}(\beta-$ decay $)$ & -15.0 \\
\hline \multirow[t]{6}{*}{${ }^{173} \mathrm{Lu}$} & $1.37 \mathrm{y}$ & $\varepsilon(100)$ & 272.11 & $21.2 \pm 0.8$ & ${ }^{170} \mathrm{Yb}(\alpha, \mathrm{p})$ & -8.7 \\
\hline & & & & & ${ }^{171} \mathrm{Yb}(\alpha, \mathrm{d})$ & -13.1 \\
\hline & & & & & ${ }^{172} \mathrm{Yb}(\alpha, \mathrm{t})$ & -14.9 \\
\hline & & & & & ${ }^{173} \mathrm{Yb}(\alpha, \operatorname{tn})$ & -21.3 \\
\hline & & & & & ${ }^{174} \mathrm{Yb}(\alpha, \mathrm{t} 2 \mathrm{n})$ & -28.7 \\
\hline & & & & & ${ }^{173} \mathrm{Hf}(\varepsilon$ decay $)$ & \\
\hline${ }^{172 \mathrm{~g} L u}$ & $6.70 \mathrm{~d}$ & $\varepsilon+\beta^{+}(100)$ & 1093.63 & $63 \pm 3$ & ${ }^{170} \mathrm{Yb}(\alpha, \mathrm{d})$ & -14.7 \\
\hline
\end{tabular}




\begin{tabular}{|c|c|c|c|c|c|c|}
\hline & & & & & ${ }^{171} \mathrm{Yb}(\alpha, \mathrm{t})$ & -15.1 \\
\hline & & & & & ${ }^{172} \mathrm{Yb}(\alpha, \operatorname{tn})$ & -23.1 \\
\hline & & & & & ${ }^{173} \mathrm{Yb}(\alpha, \mathrm{t} 2 \mathrm{n})$ & -29.5 \\
\hline & & & & & ${ }^{172} \mathrm{Hf}(\varepsilon$ decay $)$ & \\
\hline $171 \mathrm{gLu}$ & $8.24 \mathrm{~d}$ & $\varepsilon+\beta^{+}(100)$ & 739.79 & $47.9 \pm 1.3$ & ${ }^{168} \mathrm{Yb}(\alpha, \mathrm{p})$ & -8.6 \\
\hline & & & & & ${ }^{170} \mathrm{Yb}(\alpha, \mathrm{t})$ & -15.5 \\
\hline & & & & & ${ }^{171} \mathrm{Yb}(\alpha, \operatorname{tn})$ & -22.1 \\
\hline & & & & & ${ }^{172} \mathrm{Yb}(\alpha, \mathrm{t} 2 \mathrm{n})$ & -30.1 \\
\hline & & & & & ${ }^{173} \mathrm{Yb}(\alpha, \mathrm{t} 3 \mathrm{n})$ & -36.5 \\
\hline & & & & & ${ }^{174} \mathrm{Yb}(\alpha, \mathrm{t} 4 \mathrm{n})$ & -43.9 \\
\hline & & & & & ${ }^{171} \mathrm{Hf}(\varepsilon$ decay $)$ & \\
\hline${ }^{169 \mathrm{~g}} \mathrm{Yb}$ & $32.018 \mathrm{~d}$ & $\varepsilon(100)$ & 197.96 & $35.93 \pm 0.12$ & ${ }^{168} \mathrm{Yb}\left(\alpha,{ }^{3} \mathrm{He}\right)$ & -13.7 \\
\hline & & & & & ${ }^{170} \mathrm{Yb}(\alpha, \alpha \mathrm{n})$ & -8.5 \\
\hline & & & & & ${ }^{171} \mathrm{Yb}(\alpha, \alpha 2 \mathrm{n})$ & -15.1 \\
\hline & & & & & ${ }^{172} \mathrm{Yb}(\alpha, \alpha 3 \mathrm{n})$ & -23.1 \\
\hline & & & & & ${ }^{173} \mathrm{Yb}(\alpha, \alpha 4 \mathrm{n})$ & -29.5 \\
\hline & & & & & ${ }^{174} \mathrm{Yb}(\alpha, \alpha 5 \mathrm{n})$ & -36.9 \\
\hline & & & & & ${ }^{176} \mathrm{Yb}(\alpha, \alpha 7 \mathrm{n})$ & -49.6 \\
\hline & & & & & ${ }^{169} \mathrm{Hf}(\varepsilon$ decay $){ }^{169} \mathrm{Lu}(\varepsilon$ decay $)$ & \\
\hline & & & & & ${ }^{169} \mathrm{Lu}(\varepsilon$ decay $)$ & \\
\hline${ }^{51} \mathrm{Cr}$ & $27.7025 \mathrm{~d}$ & $\varepsilon(100)$ & 320.08 & $9.91 \pm 0.01$ & & \\
\hline
\end{tabular}

Cross sections $\sigma$ were deduced from measured net peak area by using the equation,

$$
\sigma=\frac{T_{\gamma} \lambda}{\varepsilon_{d} \varepsilon_{\gamma} \varepsilon_{t} N_{t} N_{b}\left(1-e^{-\lambda t_{b}}\right) e^{-\lambda t_{c}}\left(1-e^{-\lambda t_{m}}\right)}
$$

with parameters; surface density of target atoms $N_{t}$, number of bombarding particles per unit time $N_{b}$, detector efficiency $\varepsilon_{d}, \gamma$-ray abundance $\varepsilon_{\gamma}$, measurement dead time $\varepsilon_{t}$, decay constant $\lambda$, bombarding time $t_{b}$, cooling time $t_{c}$, and acquisition time $t_{m}$. The cross sections were assigned to the mid energy of each target foil.

Cross sections of the ${ }^{\text {nat }} \mathrm{Ti}(\alpha, \mathrm{x})^{51} \mathrm{Cr}$ monitor reaction were derived from measurements of the $320.08 \mathrm{keV}$ $\gamma$ line from the decay of ${ }^{51} \mathrm{Cr}\left(\mathrm{T}_{1 / 2}=27.7025 \mathrm{~d}\right)$. The dead time throughout the series of the measurements after a cooling time of 38.3 hours was kept below $0.6 \%$. The derived cross sections were compared with the IAEA recommended values [4], and the beam intensity was corrected to $379.2 \mathrm{nA}$, which was $8.4 \%$ lower than the measured value. The foil thicknesses were also adjusted only within their uncertainties $(<1 \%)$ to reach proper agreement for the energy scale. Our cross section data for the monitor reaction determined in this experiment are shown in Fig. 1 in comparison with the IAEA recommended values [4]. A complete agreement between our result and the recommended values was obtained. 


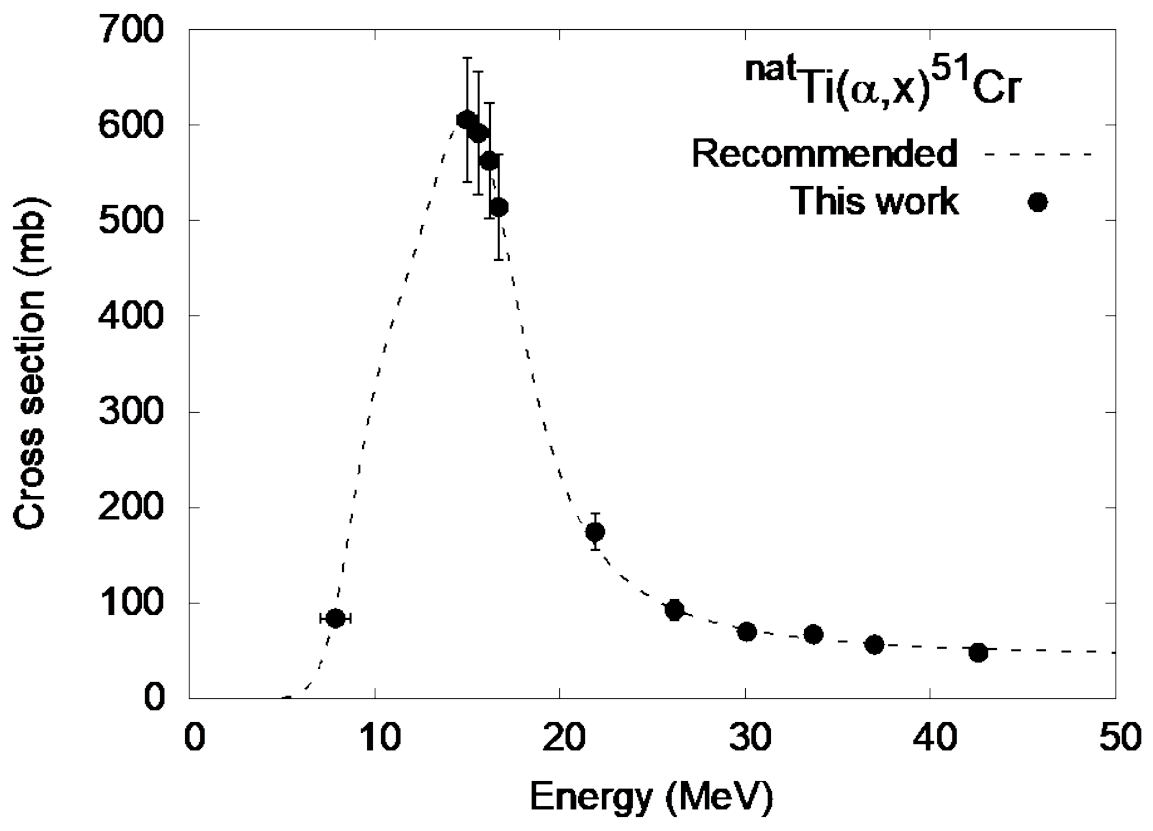

Fig. 1. Cross section data measured for the ${ }^{\mathrm{nat}} \mathrm{Ti}(\alpha, \mathrm{x})^{51} \mathrm{Cr}$ monitor reaction in comparison with the IAEA recommended values [4]. 


\section{Result and discussion}

Activation cross sections of the $\alpha$-particle induced reactions on ${ }^{\text {nat }} Y \mathrm{~b}$ were determined for the production of ${ }^{170,171,172,173,175} \mathrm{Hf},{ }^{171,172,173,177 \mathrm{~g}} \mathrm{Lu}$ and ${ }^{169} \mathrm{Yb}$ isotopes. Data are presented in Table 2 and are shown in Figs. $2-11$. The results are compared with the previous studies $[2,12,13]$ and the results of theoretical calculation taken from the TENDL-2017 data [14].

The total uncertainty of the cross sections was 11.4-36.0\% including contribution of statistical and systematical uncertainties. It was calculated from the square root of the quadratic summation of the following components; statistical uncertainty ( $<22.7 \%)$, target thickness (1\%), target purity $(1 \%)$, beam intensity $(9 \%)$, detector efficiency (5\%), $\gamma$-ray intensity ( $<26.9 \%)$, and peak fitting (3\%). Uncertainty on the time parameters (irradiation, cooling and measuring time) were not included because of the relatively long half-life of the investigated isotopes, whose contribution is negligibly small. 
Table 2. Measured ${ }^{\text {nat}} \mathrm{Yb}(\alpha, \mathrm{x})$ reaction cross sections

\begin{tabular}{|c|c|c|c|c|c|c|c|c|c|c|c|}
\hline $\begin{array}{l}\text { Energy } \\
(\mathrm{MeV})\end{array}$ & $\begin{array}{c}{ }^{\text {nat }} \mathrm{Yb}(\alpha, \mathrm{x}){ }^{175} \mathrm{Hf} \\
(\mathrm{mb})\end{array}$ & $\begin{array}{c}{ }^{\text {nat }} \mathrm{Yb}(\alpha, \mathrm{x})^{173} \mathrm{Hf} \\
(\mathrm{mb})\end{array}$ & $\begin{array}{c}{ }^{\text {nat }} \mathrm{Yb}(\alpha, \mathrm{x})^{172} \mathrm{Hf} \\
(\mathrm{mb})\end{array}$ & $\begin{array}{c}{ }^{\mathrm{nat}} \mathrm{Yb}(\alpha, \mathrm{x}){ }^{171} \mathrm{Hf} \\
(\mathrm{mb})\end{array}$ & $\begin{array}{c}{ }^{\text {nat }} \mathrm{Yb}(\alpha, \mathrm{x}){ }^{170} \mathrm{Hf} \\
(\mathrm{mb})\end{array}$ & $\begin{array}{c}{ }^{\mathrm{nat}} \mathrm{Yb}(\alpha, \mathrm{x})^{177 \mathrm{~g}} \mathrm{Lu} \\
(\mathrm{mb})\end{array}$ & $\begin{array}{c}{ }^{\mathrm{nat}} \mathrm{Yb}(\alpha, \mathrm{x})^{173} \mathrm{Lu} \\
(\mathrm{mb})\end{array}$ & $\begin{array}{c}{ }^{\text {nat }} \mathrm{Yb}(\alpha, \mathrm{x})^{172} \mathrm{Lu} \\
(\mathrm{mb})\end{array}$ & $\begin{array}{c}{ }^{\text {nat }} \mathrm{Yb}(\alpha, \mathrm{x})^{171} \mathrm{Lu}^{(\mathrm{cum})} \\
(\mathrm{mb})\end{array}$ & $\begin{array}{c}{ }^{\text {nat }} \mathrm{Yb}(\alpha, \mathrm{x})^{171} \mathrm{Lu}^{\text {(ind) }} \\
(\mathrm{mb})\end{array}$ & $\begin{array}{c}{ }^{\text {nat }} \mathrm{Yb}(\alpha, \mathrm{x})^{169} \mathrm{Yb} \\
(\mathrm{mb})\end{array}$ \\
\hline $49.4 \pm 0.7$ & $224.8 \pm 25.6$ & $538.2 \pm 62.4$ & $391.3 \pm 52.9$ & $188.8 \pm 29.7$ & $67.5 \pm 19.6$ & $23.9 \pm 2.7$ & $520.8 \pm 59.9$ & $27.7 \pm 4.3$ & $293.7 \pm 32.8$ & $110.0 \pm 19.0$ & $10.5 \pm 1.5$ \\
\hline $48.3 \pm 0.7$ & $190.8 \pm 21.8$ & $471.3 \pm 54.6$ & $345.4 \pm 46.7$ & $180.1 \pm 28.3$ & $52.7 \pm 15.3$ & $19.0 \pm 2.2$ & $449.5 \pm 51.7$ & $22.9 \pm 3.5$ & $258.3 \pm 28.8$ & $107.9 \pm 18.6$ & $8.9 \pm 1.4$ \\
\hline $47.1 \pm 0.7$ & $171.1 \pm 19.5$ & $430.3 \pm 49.9$ & $323.3 \pm 43.7$ & $156.1 \pm 24.6$ & $39.9 \pm 11.6$ & $15.7 \pm 1.8$ & $410.9 \pm 47.3$ & $19.4 \pm 3.0$ & $225.9 \pm 25.2$ & $79.5 \pm 13.8$ & $6.5 \pm 1.1$ \\
\hline $46.0 \pm 0.7$ & $163.0 \pm 18.6$ & $419.4 \pm 48.6$ & $307.9 \pm 41.6$ & $146.0 \pm 23.0$ & $33.2 \pm 9.7$ & $13.8 \pm 1.6$ & $395.1 \pm 45.4$ & $17.2 \pm 2.7$ & $208.5 \pm 23.3$ & $78.5 \pm 13.8$ & $7.8 \pm 1.1$ \\
\hline $44.8 \pm 0.7$ & $174.4 \pm 19.9$ & $450.6 \pm 52.2$ & $307.2 \pm 41.5$ & $143.5 \pm 22.5$ & $32.5 \pm 9.6$ & $12.6 \pm 1.5$ & $425.4 \pm 48.9$ & $16.6 \pm 2.6$ & $203.3 \pm 22.7$ & $71.5 \pm 13.9$ & $6.5 \pm 1.0$ \\
\hline $43.6 \pm 0.7$ & $180.4 \pm 20.6$ & $434.9 \pm 50.4$ & $282.6 \pm 38.3$ & $117.6 \pm 18.4$ & $21.1 \pm 6.2$ & $10.2 \pm 1.1$ & $412.5 \pm 47.4$ & $13.5 \pm 2.1$ & $166.6 \pm 18.6$ & $62.2 \pm 10.8$ & $5.7 \pm 1.0$ \\
\hline $40.6 \pm 0.7$ & $310.3 \pm 35.4$ & $490.4 \pm 56.8$ & $250.1 \pm 34.2$ & $70.7 \pm 11.1$ & $2.3 \pm 0.8$ & $8.7 \pm 1.0$ & $456.7 \pm 52.7$ & $11.1 \pm 1.7$ & $103.4 \pm 11.5$ & $35.5 \pm 6.1$ & $4.8 \pm 0.5$ \\
\hline $39.4 \pm 0.7$ & $376.9 \pm 43.0$ & $477.8 \pm 55.3$ & $227.4 \pm 30.9$ & $51.3 \pm 8.1$ & $1.5 \pm 0.5$ & $7.4 \pm 0.8$ & $435.8 \pm 50.1$ & $9.0 \pm 1.4$ & $75.2 \pm 8.4$ & $26.0 \pm 4.5$ & $3.9 \pm 0.4$ \\
\hline $38.1 \pm 0.8$ & $433.8 \pm 49.4$ & $439.2 \pm 50.9$ & $199.7 \pm 27.2$ & $37.4 \pm 5.9$ & & $6.4 \pm 0.7$ & $405.5 \pm 46.6$ & $7.2 \pm 1.1$ & $55.3 \pm 6.2$ & $19.4 \pm 3.4$ & $3.0 \pm 0.4$ \\
\hline $34.9 \pm 0.8$ & $490.0 \pm 55.8$ & $367.9 \pm 42.6$ & $168.4 \pm 23.0$ & $23.6 \pm 3.7$ & & $4.4 \pm 0.5$ & $335.5 \pm 38.6$ & $3.9 \pm 0.6$ & $32.7 \pm 3.6$ & $9.9 \pm 1.8$ & $1.0 \pm 0.1$ \\
\hline $31.4 \pm 0.9$ & $436.1 \pm 49.7$ & $306.1 \pm 35.5$ & $111.1 \pm 15.2$ & $6.9 \pm 1.1$ & & $3.8 \pm 0.5$ & $271.7 \pm 31.2$ & $2.4 \pm 0.4$ & $9.1 \pm 1.0$ & $2.5 \pm 0.6$ & \\
\hline $27.6 \pm 0.9$ & $225.7 \pm 25.7$ & $187.2 \pm 21.7$ & $32.9 \pm 4.6$ & & & $2.2 \pm 0.3$ & $163.3 \pm 18.7$ & $0.82 \pm 0.14$ & $0.35 \pm 0.04$ & & \\
\hline $23.4 \pm 1.1$ & $129.9 \pm 14.8$ & $112.0 \pm 13.0$ & $13.7 \pm 1.9$ & & & $0.52 \pm 0.10$ & $97.0 \pm 11.1$ & & $0.55 \pm 0.06$ & & \\
\hline $18.6 \pm 1.3$ & $33.5 \pm 3.8$ & $9.2 \pm 1.1$ & & & & & $7.9 \pm 0.9$ & & $0.20 \pm 0.02$ & & \\
\hline
\end{tabular}




\section{$3.1^{\text {nat }} \mathbf{Y b}(\alpha, \mathbf{x})^{175} \mathrm{Hf}$ reaction}

Experimental cross sections of the ${ }^{\text {nat }} \mathrm{Yb}(\alpha, \mathrm{x})^{175} \mathrm{Hf}$ process were derived from measurements of the $\gamma$ line at $343.40 \mathrm{keV}\left(\mathrm{I}_{\gamma}=84 \%\right)$. The measurements were performed after a cooling time of 143 days to reduce unnecessary background. The result shown in Fig. 2 is compared with the previous studies [2,12] and the TENDL-2017 data [14]. The previous data are consistent with our result, however the TENDL-2017 data underestimate all experimental data.

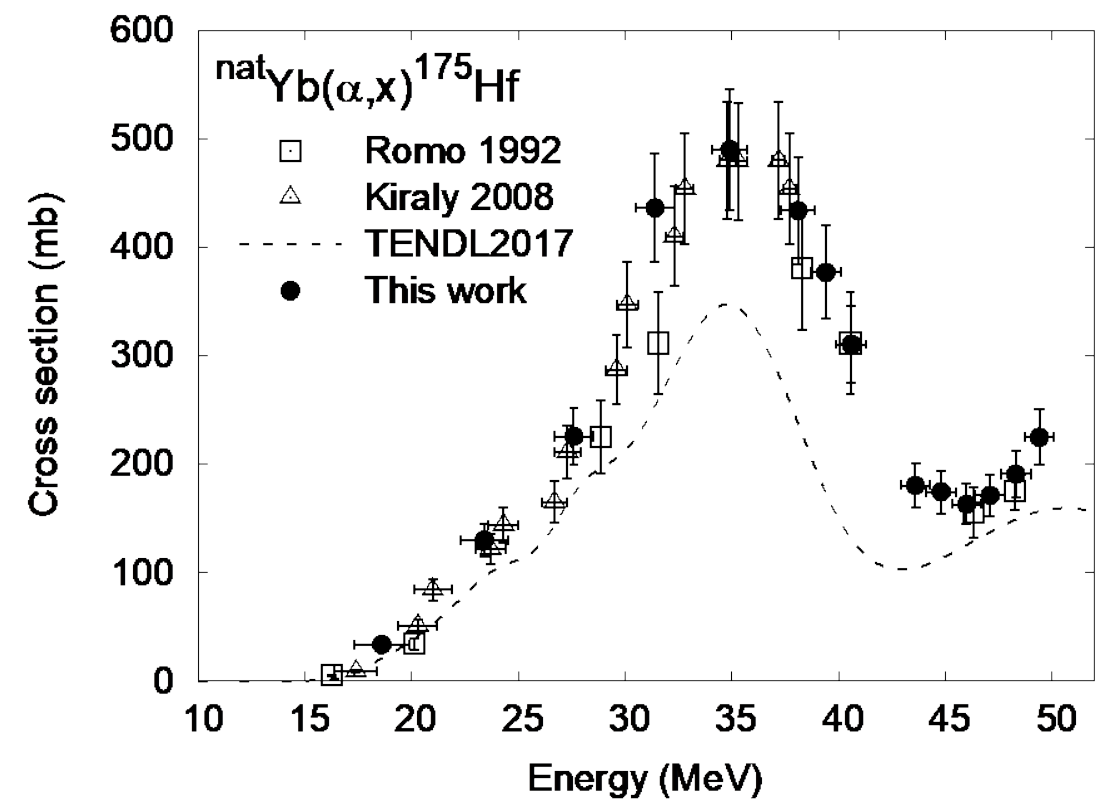

Fig. 2. Cross sections of the natYb( $\alpha, \mathrm{x}){ }^{175} \mathrm{Hf}$ reaction with the previous data $[2,12]$ and the TENDL-2017 data [14]. 


\section{$3.2^{\text {nat }} \mathbf{Y b}(\alpha, x)^{173} \mathrm{Hf}$ reaction}

Measurements of the $\gamma$ line at $296.97 \mathrm{keV}\left(\mathrm{I}_{\gamma}=33.9 \%\right)$ from the decay of ${ }^{173} \mathrm{Hf}\left(\mathrm{T}_{1 / 2}=23.6 \mathrm{~h}\right)$ were performed after a cooling time of 10 hours. The more intense $\gamma$ line at $123.68 \mathrm{keV}\left(\mathrm{I}_{\gamma}=83 \%\right)$ was not selected because of possible interferences with the $\gamma$ lines at 124.4 and $124.6 \mathrm{keV}$ from ${ }^{171 \mathrm{~g}} \mathrm{Hf}\left(\mathrm{T}_{1 / 2}=12.1 \mathrm{~h}\right)$. The obtained cross sections are shown in Fig. 3 in comparison with the data of the previous study [2] and the TENDL-2017 data [14]. The previous data are slightly smaller than our data. The TENDL-2017 data underestimate our data though they agree with the previous data.

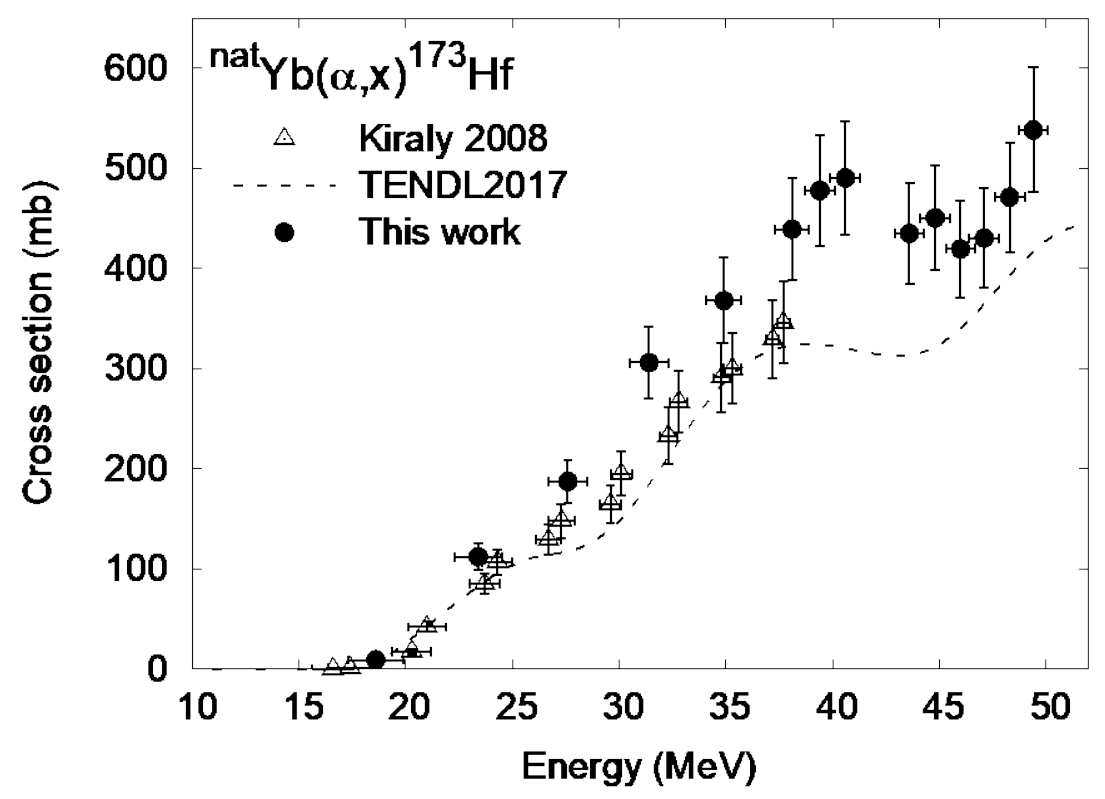

Fig. 3. Cross sections of the natYb( $\alpha, x){ }^{173} \mathrm{Hf}$ reaction with the previous data [2] and the TENDL-2017 data [14]. 


\section{$3.3^{\text {nat }} \mathbf{Y b}(\alpha, \mathbf{x})^{172} \mathbf{H f}$ reaction}

The radionuclide ${ }^{172} \mathrm{Hf}\left(\mathrm{T}_{1 / 2}=1.87 \mathrm{y}\right)$ decays with emission of the $\gamma$ rays with $125.81 \mathrm{keV}\left(\mathrm{I}_{\gamma}=11.3 \%\right)$, which was used to determine the excitation function of the ${ }^{\text {nat }} \mathrm{Yb}(\alpha, x){ }^{172} \mathrm{Hf}$ reaction. The series of the measurements after a cooling time of 143 days was used. The results are shown in Fig. 4 and compared with the previous studies [12,13] and the TENDL-2017 data [14]. Both previous data and the TENDL-2017 data are in good agreement with our data.

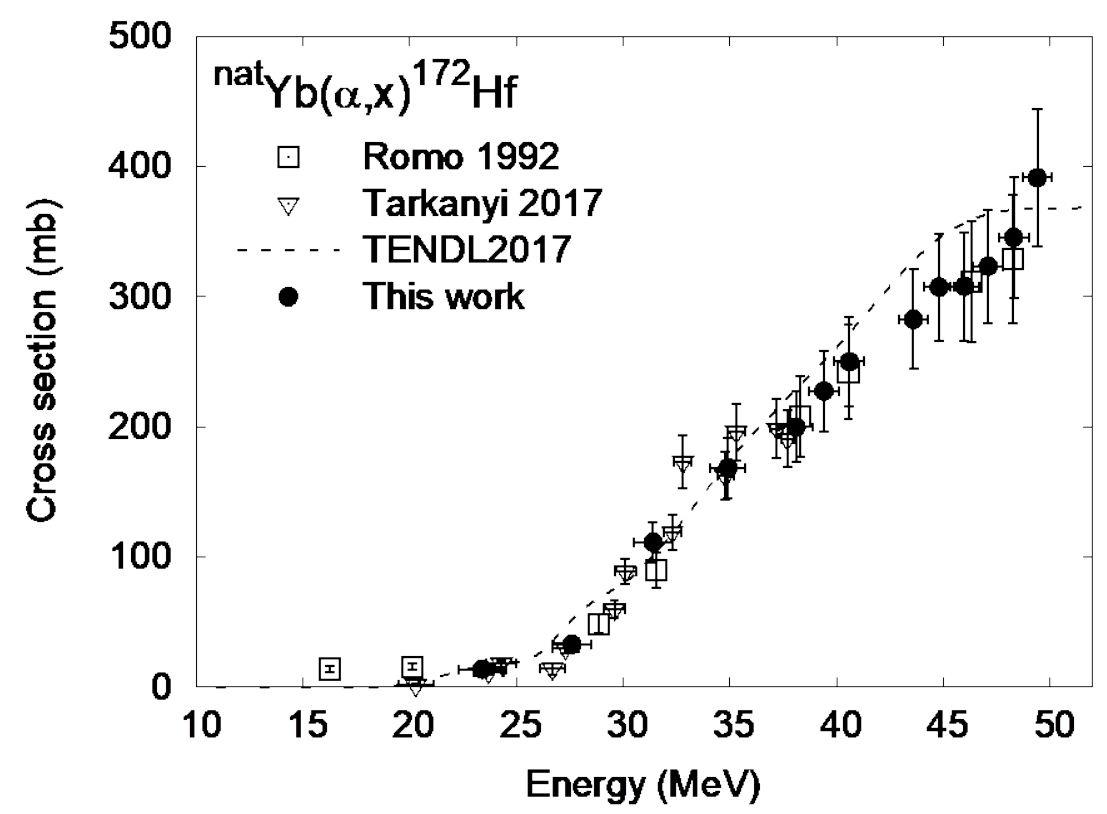

Fig. 4. Cross sections of the natYb( $\alpha, x)^{172} \mathrm{Hf}$ reaction with the previous data $[12,13]$ and the TENDL-2017 data [14]. 


\section{$3.4^{\text {nat }} \mathbf{Y b}(\alpha, \mathbf{x})^{171} \mathrm{Hf}$ reaction}

Only relative $\gamma$-ray intensity is available for ${ }^{171} \mathrm{Hf}\left(\mathrm{T}_{1 / 2}=16.01 \mathrm{~h}\right)$ in the Lund/LBNL Nuclear Data library [8]. To obtain the absolute cross sections, the normalization factor reported by Baglin (2002) [11] was adopted for the relative intensity in the same as the previous study [2]. The specific $\gamma$ line at $662.2 \mathrm{keV}\left(\mathrm{I}_{\gamma}=\right.$ 14.6\%) were measured after a cooling time of 33 hours. The cross sections of the ${ }^{\text {nat }} \mathrm{Yb}(\alpha, \mathrm{x})^{171} \mathrm{Hf}$ reaction are shown in Fig. 5. The results are compared with the previous study [2] and the TENDL-2017 data [14]. The previous data and our data are in good agreement with each other, while the TENDL-2017 data are higher than the experimental data above $30 \mathrm{MeV}$.

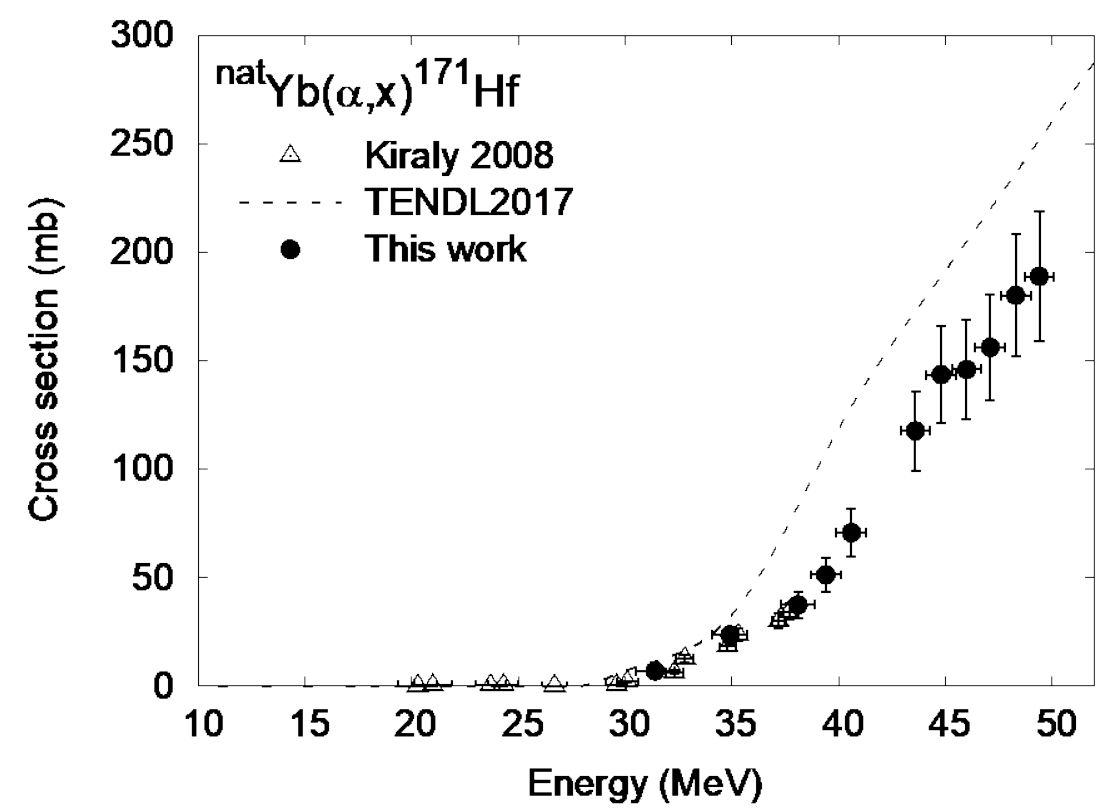

Fig. 5. Cross sections of the nat $\mathrm{Yb}(\alpha, \mathrm{x}){ }^{171} \mathrm{Hf}$ reaction with the previous data [2] and the TENDL-2017 data [14]. 


\section{$3.5^{\text {nat }} \mathbf{Y b}(\alpha, \mathbf{x})^{170} \mathrm{Hf}$ reaction}

We adopted the $\gamma$ line at $164.71 \mathrm{keV}\left(\mathrm{I}_{\gamma}=26 \%\right)$ to derive the cross sections of the ${ }^{\text {nat }} \mathrm{Yb}(\alpha, \mathrm{x})^{170} \mathrm{Hf}$ reaction. The radionuclide ${ }^{170} \mathrm{Hf}$ has a half-life $\mathrm{T}_{1 / 2}=16.01 \mathrm{~h}$. The measurements after a cooling time of about 33 hours were used for the cross section determination. The cross sections are shown in Fig. 6 in comparison with the previous study [2] and the TENDL-2017 data [14]. The previous dataset is available up to $37.7 \mathrm{MeV}$ while ours is between $39.4 \mathrm{MeV}$ and 49.4 MeV. Since the previous cross sections at $37.7 \mathrm{MeV}$ and ours at 39.4 $\mathrm{MeV}$ are $1.24 \pm 0.38 \mathrm{mb}$ and $1.5 \pm 0.5 \mathrm{mb}$, respectively, the two excitation functions can be connected smoothly. The TENDL-2017 data show the similar shape as the experimental data, however with higher amplitude above $37 \mathrm{MeV}$.

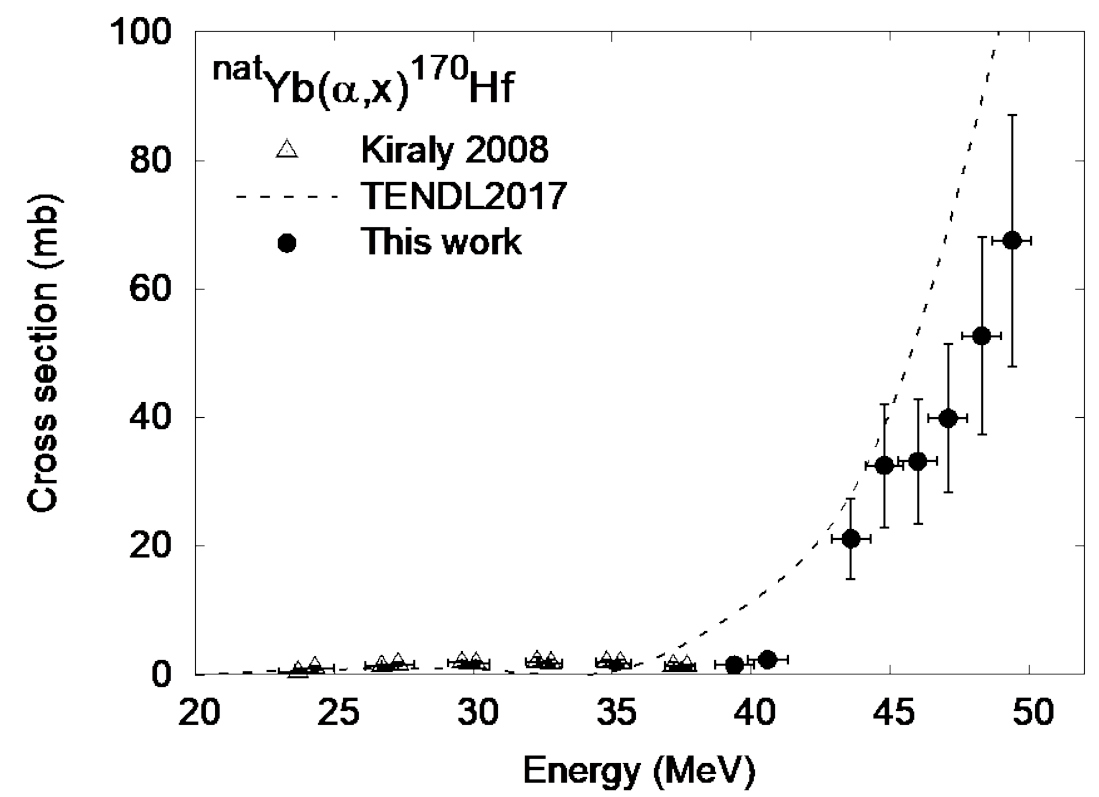

Fig. 6. Cross sections of the nat $\mathrm{Yb}(\alpha, \mathrm{x})^{170} \mathrm{Hf}$ reaction with the previous data [2] and the TENDL-2017 data [14]. 


\section{$3.6^{\text {nat }} \mathbf{Y b}(\alpha, x)^{177 g} \mathrm{Lu}$ reaction}

To determine the cumulative production cross sections of ${ }^{177 g} \mathrm{Lu}\left(\mathrm{T}_{1 / 2}=6.647 \mathrm{~d}\right)$, the measurements of the $\gamma$ line at $208.37 \mathrm{keV}\left(\mathrm{I}_{\gamma}=10.36 \%\right)$ were performed after a cooling time of 3.1 days to decay out its parent nuclide ${ }^{177} \mathrm{Yb}\left(\mathrm{T}_{1 / 2}=1.911 \mathrm{~h}\right)$. The negligible contribution of ${ }^{177 \mathrm{~m}} \mathrm{Lu}\left(\mathrm{T}_{1 / 2}=160.44 \mathrm{~d}, \beta=78.60 \%\right.$, IT: 21.40\%) could be confirmed using the measurements of a cooling time of 143 days. The cumulative cross sections of the ${ }^{\text {nat }} \mathrm{Yb}(\alpha, \mathrm{x})^{177 \mathrm{~g}} \mathrm{Lu}$ reaction are compared with the previous study [2] and the TENDL-2017 data [14] in Fig. 7. The previous data are in good agreement with the present data. The TENDL-2017 data are much smaller than the experimental data.

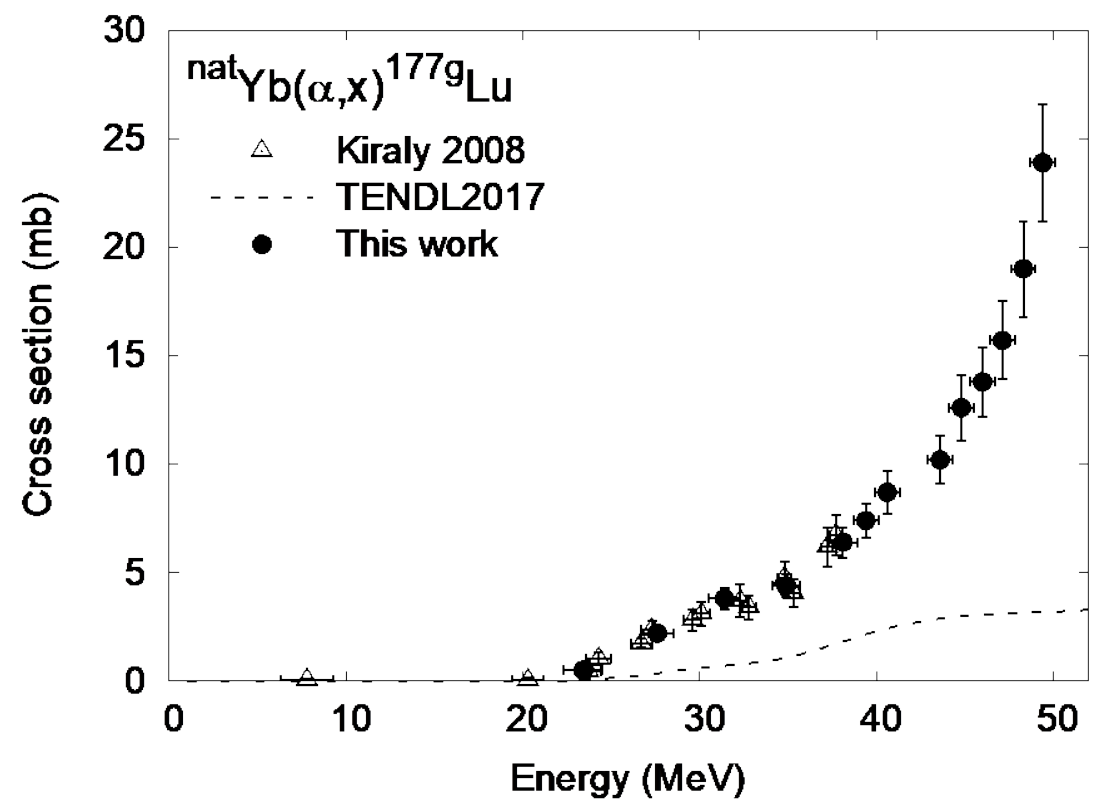

Fig. 7. Cross sections of the ${ }^{n a t} \mathrm{Yb}(\alpha, \mathrm{x}){ }^{177 \mathrm{~g}} \mathrm{Lu}$ reaction with the previous data [2] and the TENDL-2017 data [14]. 


\section{$3.7^{\text {nat }} \mathbf{Y b}(\alpha, \mathbf{x})^{173} \mathbf{L u}$ reaction}

For the cumulative cross sections of the ${ }^{\text {nat }} \mathrm{Yb}(\alpha, \mathrm{x})^{173} \mathrm{Lu}$ reaction, we used the series of the measurements after a cooling time of 143 days to decay out its parent nuclide ${ }^{173} \mathrm{Hf}\left(\mathrm{T}_{1 / 2}=23.6 \mathrm{~h}\right)$. The radionuclide ${ }^{173} \mathrm{Lu}$ has a half-life of $\mathrm{T}_{1 / 2}=1.37 \mathrm{y}$ and decays with emission of the $\gamma$ rays with $272.11 \mathrm{keV}\left(\mathrm{I}_{\gamma}=21.2 \%\right)$. The cross sections were compared with the previous studies [12,13] and the TENDL-2017 data [14] in Fig. 8. The previous data show higher amplitude than ours. On the contrary, the TENDL-2017 data are smaller than our experimental data.

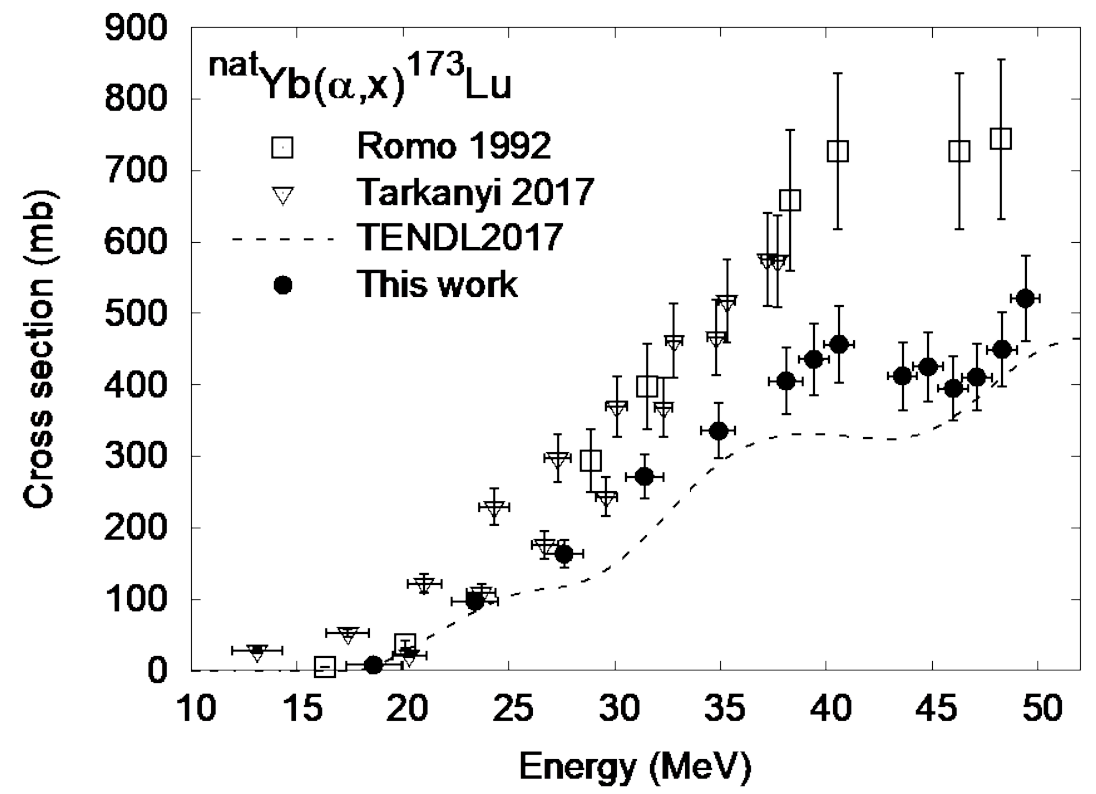

Fig. 8. Cross sections of the nat $\mathrm{Yb}(\alpha, \mathrm{x})^{173} \mathrm{Lu}$ reaction with the previous data $[12,13]$ and the TENDL-2017 data [14]. 


\section{$3.8^{\text {nat }} \mathbf{Y b}(\alpha, \mathbf{x})^{172}$ Lu reaction}

The radionuclide ${ }^{172} \mathrm{Lu}$ has a metastable state ${ }^{172 \mathrm{~m}} \mathrm{Lu}\left(\mathrm{T}_{1 / 2}=3.7 \mathrm{~min}\right.$, IT: $\left.100 \%\right)$. The metastable state decayed to the ground state ${ }^{172 g} \mathrm{Lu}\left(\mathrm{T}_{1 / 2}=6.7 \mathrm{~d}\right)$ during a cooling time of 3.1 days. The $\gamma$ line at $1093.63 \mathrm{keV}$ $\left(\mathrm{I}_{\gamma}=63 \%\right)$ was measured to derive the cross sections of the ${ }^{\text {nat }} \mathrm{Yb}(\alpha, \mathrm{x})^{172} \mathrm{Lu}$ reaction. The contribution of ${ }^{172} \mathrm{Hf}\left(\mathrm{T}_{1 / 2}=1.87 \mathrm{y}\right)$ was corrected using the cross sections derived in section 3.3. The excitation function is shown in Fig. 9 in comparison with the previous studies [2,12] and the TENDL-2017 data [14]. The previous data show higher amplitude than the present data. The TENDL-2017 data are smaller than both the previous and our experimental data.

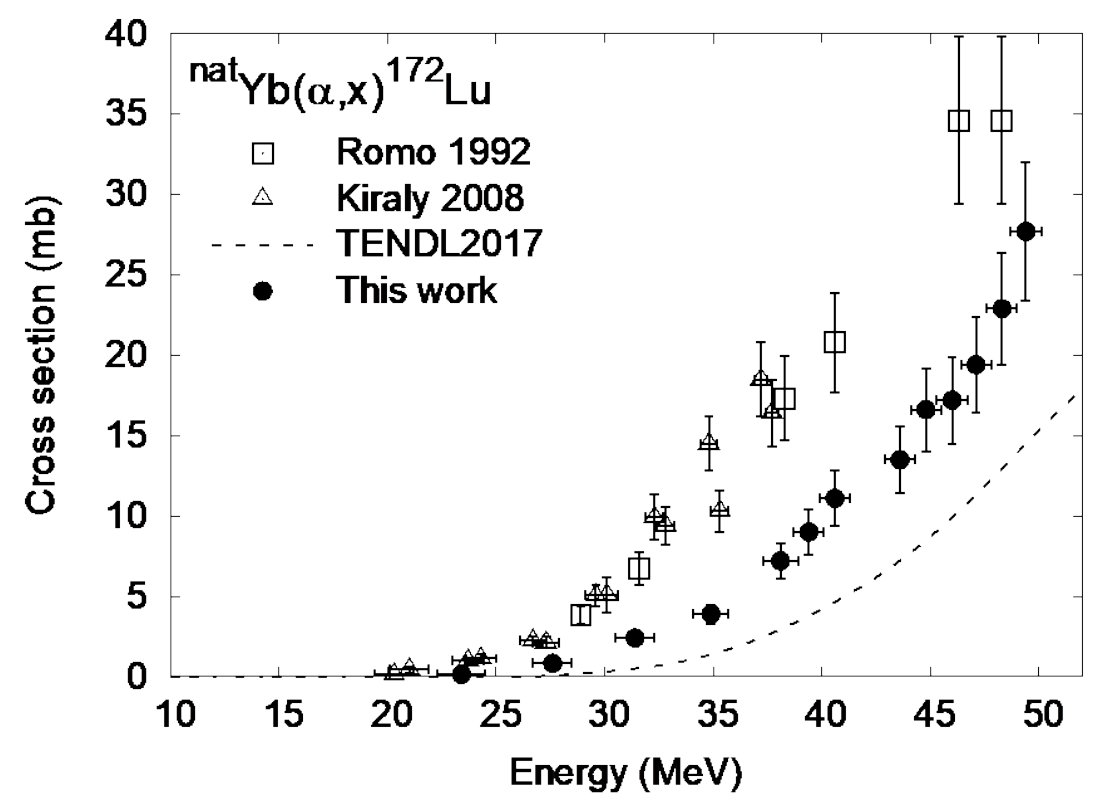

Fig. 9. Cross sections of the ${ }^{n a t} \mathrm{Yb}(\alpha, \mathrm{x}){ }^{172} \mathrm{Lu}$ reaction with the previous data $[2,12]$ and the TENDL-2017 data [14]. 


\section{$3.99^{\text {nat }} \mathbf{Y b}(\alpha, \mathbf{x})^{171} \mathrm{Lu}$ reaction}

The metastable state of ${ }^{171 \mathrm{~m}} \mathrm{Lu}\left(\mathrm{T}_{1 / 2}=79 \mathrm{~s}\right.$, IT: $\left.100 \%\right)$ contributed to the formation of ground state ${ }^{171 \mathrm{~g}} \mathrm{Lu}$ $\left(\mathrm{T}_{1 / 2}=8.24 \mathrm{~d}\right)$ during the beam irradiation and shortly after the end of bombardment. The measurements of the $\gamma$ line at $739.79 \mathrm{keV}\left(\mathrm{I}_{\gamma}=47.9 \%\right)$ after a cooling time of 3.1 days were used to derive cross sections of the ${ }^{\text {nat }} \mathrm{Yb}(\alpha, \mathrm{x})^{171} \mathrm{Lu}$ reaction. The contribution of its parent ${ }^{171} \mathrm{Hf}$ can be corrected using the cross sections derived in section 3.4. In Fig. 10, both the cumulative and independent cross section data sets, which include (cum) and exclude (ind) the contribution of ${ }^{171} \mathrm{Hf}$, are shown. The cumulative data in the previous studies $[2,12]$ show good agreement with ours and the TENDL-2017 data [14].

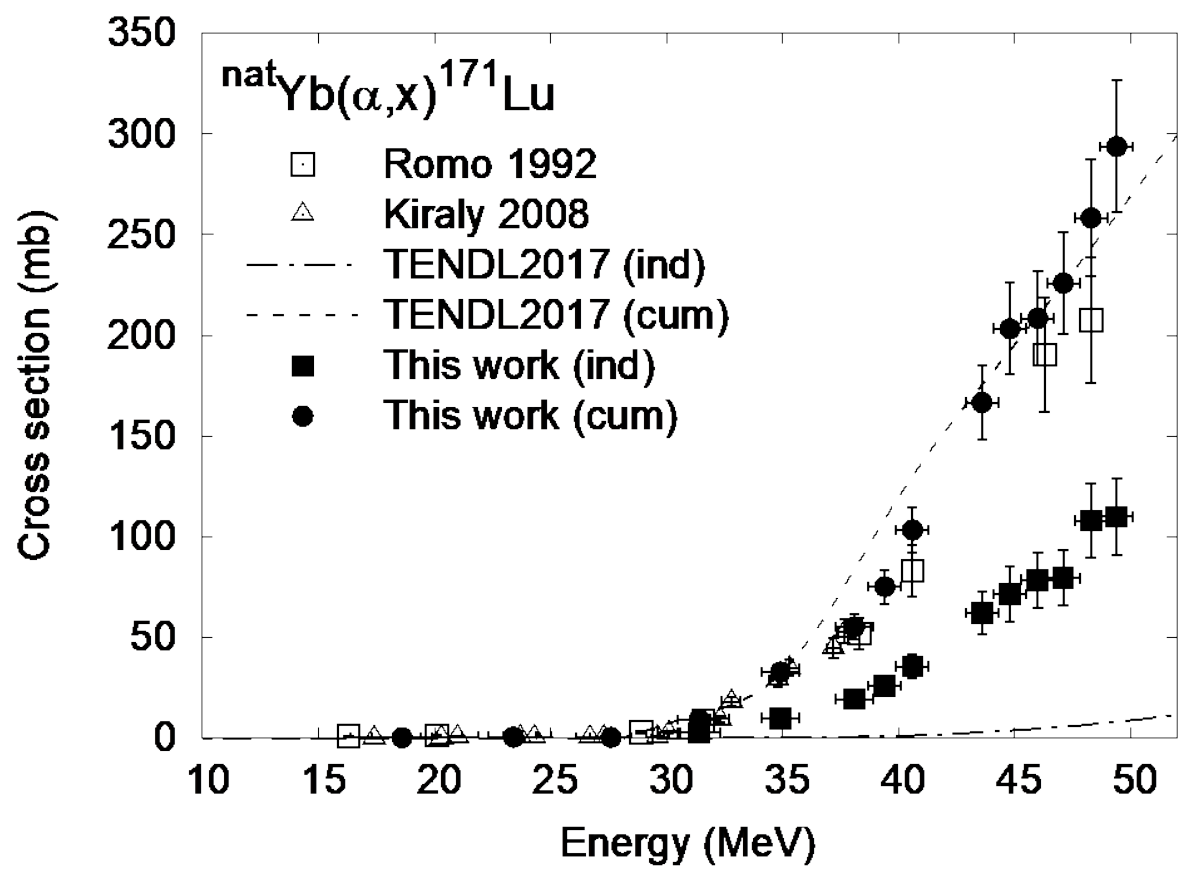

Fig. 10. Cross sections of the ${ }^{n a t} \mathrm{Yb}(\alpha, \mathrm{x})^{171} \mathrm{Lu}$ reaction with the previous data $[2,12]$ and the TENDL-2017 data [14]. 


\section{$3.10{ }^{\text {nat }} \mathbf{Y b}(\alpha, \mathbf{x})^{169} \mathbf{Y b}$ reaction}

The radionuclide ${ }^{169} \mathrm{Yb}$ has a metastable state ${ }^{169 \mathrm{~m}} \mathrm{Yb}$ with a short half-life of $\mathrm{T}_{1 / 2}=46 \mathrm{~s}$ (IT: 100\%), which decayed to ${ }^{169 g} \mathrm{Yb}\left(\mathrm{T}_{1 / 2}=32.018 \mathrm{~d}\right)$ during the irradiation and a cooling time of 14.1 days. Cross sections of the ${ }^{\text {nat }} \mathrm{Yb}(\alpha, \mathrm{x})^{169} \mathrm{Yb}$ reaction were derived using the $\gamma$ line at $197.96 \mathrm{keV}\left(\mathrm{I}_{\gamma}=35.93 \%\right)$. The present results are compared with the previous studies [2,12] and the TENDL-2017 data [14] in Fig. 11. One set of data of the previous work [2] shows good agreement with the present data. The TENDL-2017 data overestimate ours.

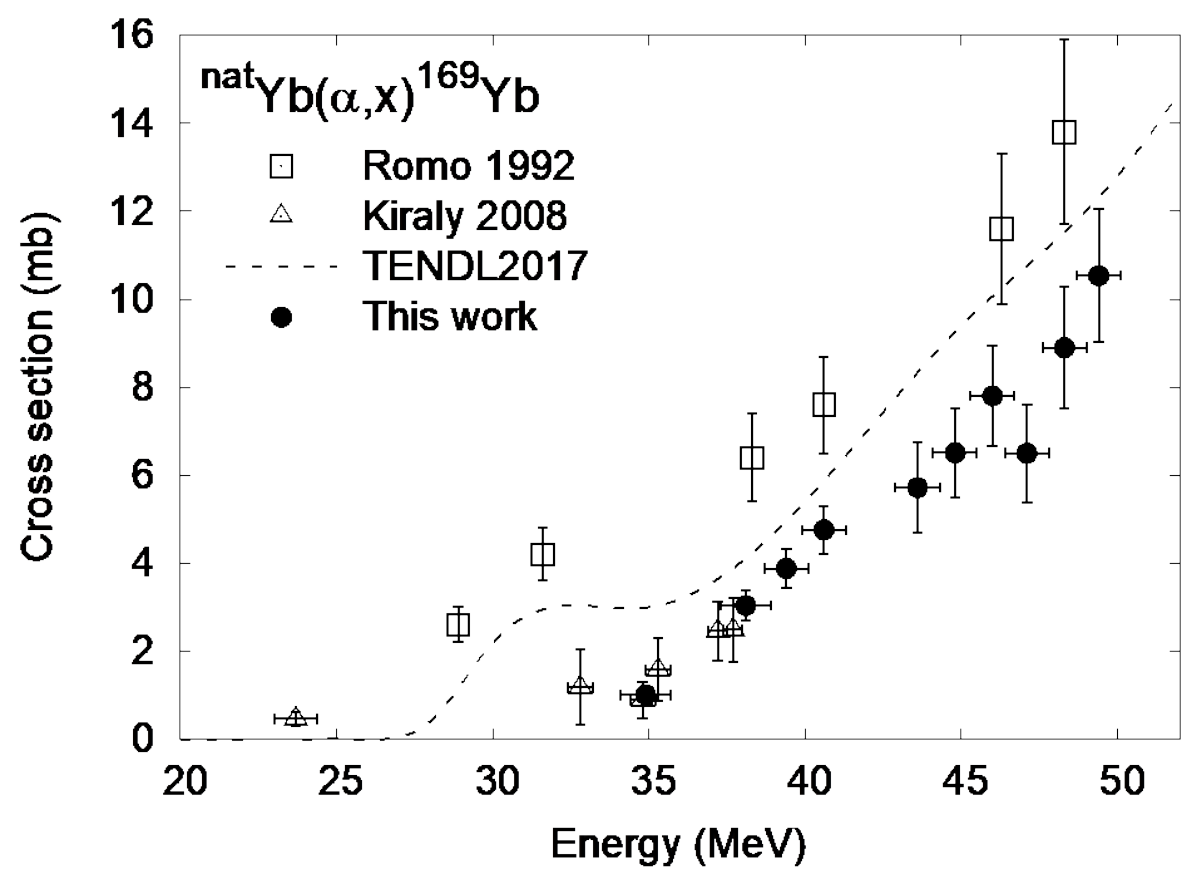

Fig. 11. Cross sections of the ${ }^{\mathrm{nat}} \mathrm{Yb}(\alpha, \mathrm{x})^{169} \mathrm{Yb}$ reaction with the previous data $[2,12]$ and the TENDL-2017 data [14]. 


\section{Summary}

We measured activation cross sections of the $\alpha$-particle induced reactions on ${ }^{\text {nat }} Y b$ using the stacked target activation technique and high resolution $\gamma$-ray spectrometry. Four series of the activity measurements were performed for radionuclides with largely different half-lives. The production cross sections of ${ }^{170,171,172,173,175} \mathrm{Hf},{ }^{171,172,173,177 \mathrm{~g}} \mathrm{Lu}$ and ${ }^{169} \mathrm{Yb}$ were determined. The measured data were compared with the previous experimental data and the theoretical data of TENDL-2017 data library. For most of the reactions, good agreement was found with the previous studies.

\section{Acknowledgements}

This work was carried out at the RI Beam Factory operated by RIKEN Nishina Center and CNS, University of Tokyo, Japan. Preliminary results were presented at the $18^{\text {th }}$ Radiochemical Conference (RadChem 2018) held in Mariánské Lázně, Czech Republic, on 13-18 May 2018. This work was supported by Hokkaido University Nitobe School Advanced Program Research Grant 2017 from the Hokkaido University's Frontier Foundation and JSPS KAKENHI Grant Number 17K07004.

\section{Declarations of interest}

none

\section{References}

[1] K. Rahbar, H. Ahmadzadehfar, C. Kratochwil, U. Haberkorn, M. Schäfers, M. Essler, R.P. Baum, H.R. Kulkarni, M. Schmidt, A. Drzezga, P. Bartenstein, A. Pfestroff, M. Luster, U. Lützen, M. Marx, V. Prasad, W. Brenner, A. Heinzel, F.M. Mottaghy, J. Ruf, P.T. Meyer, M. Heuschkel, M. Eveslage, M. Bögemann, W.P. Fendler, B.J. Krause, German Multicenter Study Investigating 177 Lu-PSMA-617 Radioligand Therapy in Advanced Prostate Cancer Patients, J. Nucl. Med. 58 (2017) 85-90. doi:10.2967/jnumed.116.183194.

[2] B. Király, F. Tárkányi, S. Takács, A. Hermanne, S.F. Kovalev, A. V. Ignatyuk, Excitation functions of alpha-particle induced nuclear reactions on natural ytterbium, Nucl. Instruments Methods Phys. Res. Sect. B Beam Interact. with Mater. Atoms. 266 (2008) 3919-3926. doi:10.1016/j.nimb.2008.07.002.

[3] N. Otuka, E. Dupont, V. Semkova, B. Pritychenko, A.I. Blokhin, M. Aikawa, S. Babykina, M. Bossant, G. Chen, S. Dunaeva, R.A. Forrest, T. Fukahori, N. Furutachi, S. Ganesan, Z. Ge, O.O. Gritzay, M. Herman, S. Hlavač, K. Kato, B. Lalremruata, Y.O. Lee, A. Makinaga, K. Matsumoto, M. Mikhaylyukova, G. Pikulina, V.G. Pronyaev, A. Saxena, O. Schwerer, S.P. Simakov, N. Soppera, R. Suzuki, S. Takács, X. Tao, S. Taova, F. Tárkányi, V. V. Varlamov, J. Wang, S.C. Yang, V. Zerkin, Y. Zhuang, Towards a More complete and accurate experimental nuclear reaction data library (EXFOR): International collaboration between nuclear reaction data centres (NRDC), Nucl. Data Sheets. 120 (2014) 272-276. doi:10.1016/j.nds.2014.07.065. 
[4] A. Hermanne, A. V. Ignatyuk, R. Capote, B. V. Carlson, J.W. Engle, M.A. Kellett, T. Kibédi, G. Kim, F.G. Kondev, M. Hussain, O. Lebeda, A. Luca, Y. Nagai, H. Naik, A.L. Nichols, F.M. Nortier, S. V. Suryanarayana, S. Takács, F.T. Tárkányi, M. Verpelli, Reference Cross Sections for Charged-particle Monitor Reactions, Nucl. Data Sheets. 148 (2018) 338-382. doi:10.1016/j.nds.2018.02.009.

[5] T. Watanabe, M. Fujimaki, N. Fukunishi, H. Imao, O. Kamigaito, M. Kase, M. Komiyama, N. Sakamoto, K. Suda, M. Wakasugi, K. Yamada, Beam energy and longitudinal beam profile measurement system at the RIBF, in: Proc. 5th Int. Part. Accel. Conf. (IPAC 2014), 2014: pp. 35663568.

[6] J.F. Ziegler, J.P. Biersack, M.D. Ziegler, SRIM: the Stopping and Range of Ions in Matter, (2008). http://www.srim.org.

[7] National Nuclear Data Center, Nuclear structure and decay data on-line library, Nudat 2.7, (2017). http://www.nndc.bnl.gov/nudat2/.

[8] S.Y.F. Chu, L.P. Ekström, R.B. Firestone, The Lund/LBNL Nuclear Data Search, (n.d.). http://nucleardata.nuclear.lu.se/toi/.

[9] International Atomic Energy Agency, LiveChart of Nuclides, (2009). https://wwwnds.iaea.org/livechart/.

[10] B. Pritychenko, A. Sonzogni, Q-value Calculator (QCalc), (2003). http://www.nndc.bnl.gov/qcalc/.

[11] C.M. Baglin, Nuclear Data Sheets for A = 171, Nucl. Data Sheets. 96 (2002) 399-610. doi:10.1006/ndsh.2002.0014.

[12] A.S.M.A. Romo, A.A. Sonzogni, D.A. Rodriguez Sierra, S.J. Nassiff, Nuclear Reactions Induced by Alpha Particles on Natural Ytterbium, Radiochim. Acta. 57 (1992) 57-61. doi:10.1524/ract.1992.57.23.57.

[13] F. Tárkányi, F. Ditrói, S. Takács, A. Hermanne, B. Király, Activation cross-section data for alphaparticle induced nuclear reactions on natural ytterbium for some longer lived radioisotopes, J. Radioanal. Nucl. Chem. 311 (2017) 1825-1829. doi:10.1007/s10967-016-5139-0.

[14] A.J. Koning, D. Rochman, J. Sublet, N. Dzysiuk, M. Fleming, S. van der Marck, TENDL: Complete Nuclear Data Library for Innovative Nuclear Science and Technology, Nucl. Data Sheets. 155 (2019) 155. doi:10.1016/j.nds.2019.01.002. 